\title{
Miliary tuberculosis with hypercalcaemia and raised vitamin D concentrations
}

\author{
R D ISAACS, G I NICHOLSON, I M HOLDAWAY \\ From the Department of Respiratory Medicine, Green Lane Hospital, and the Departments of Gastroenterology \\ and Endocrinology, Auckland Hospital, Auckland, New Zealand
}

Hypercalcaemia is associated with granulomatous disorders, including sarcoidosis ${ }^{1}$ and tuberculosis. ${ }^{2-4}$ The exact incidence of hypercalcaemia in tuberculosis is not known. We report a case of miliary tuberculosis and severe hypercalcaemia in which measurements of serum vitamin $D_{3}$ concentrations were made. The probable mechanism of the hypercalcaemia is discussed.

\section{Case report}

A 44 year old man, a Cook Islander and a non-smoker, presented with an eight month history of lethargy and malaise, a three month history of ascites, and a one month history of polyuria and polydipsia. Abdominal paracentesis had been performed at another hospital but the results of this were not available. Histological examination of a right cervical lymph node showed caseating granulomas typical of tuberculosis. Subsequent cultures of the lymph node, sputum, resting gastric juices, and early morning urine samples grew Mycobacterium tuberculosis, sensitive in vitro to isoniazid, rifampicin, and pyrazinamide.

Initial biochemical investigation of the blood revealed hyponatraemia, hypercalcaemia (figure), and no evidence of abnormal renal function. An adrenocorticotrophic hormone stimulation test yielded normal results, as did tests of thyroid function. The serum parathyroid hormone concentration was $20.6 \mathrm{pmol} / \mathrm{l}$, measured in a mid molecule radioimmunoassay (normal 6.0-31.5 pmol/l). Alkaline phosphatase activity was normal and a technetium-99m bone scan showed nothing to suggest malignant disease. A chest radiograph showed miliary shadowing with no focal changes. A computed tomographic scan of the abdomen revealed mesenteric lymphadenopathy, thickened omentum, and the presence of ascites. The liver, spleen, adrenal glands, and kidneys were unremarkable. An intravenous urogram was normal. There was no evidence of lymphoreticular malignancy.

Vitamin D studies (figure) before lymph node biopsy showed depression of 25-hydroxy vitamin $\mathrm{D}_{3}\left(25-\mathrm{OHD}_{3}\right)$ concentrations with raised 1,25-dihydroxy vitamin $D_{3}$ $\left(1,25(\mathrm{OH})_{2} \mathrm{D}_{3}\right)$ concentrations. Before lymph node biopsy he received an infusion of the diphosphonate APD (3-amino-1-hydroxy propylidene-1,1-biphosphonate) $0 \cdot 3$ $\mathrm{mg} / \mathrm{kg}$ on two consecutive days, which produced a prompt fall in serum calcium concentration. After the diagnosis of

Address for reprint requests: Professor I M Holdaway, Department of Endocrinology, Auckland Hospital, Auckland 1, New Zealand.

Accepted 15 July 1986
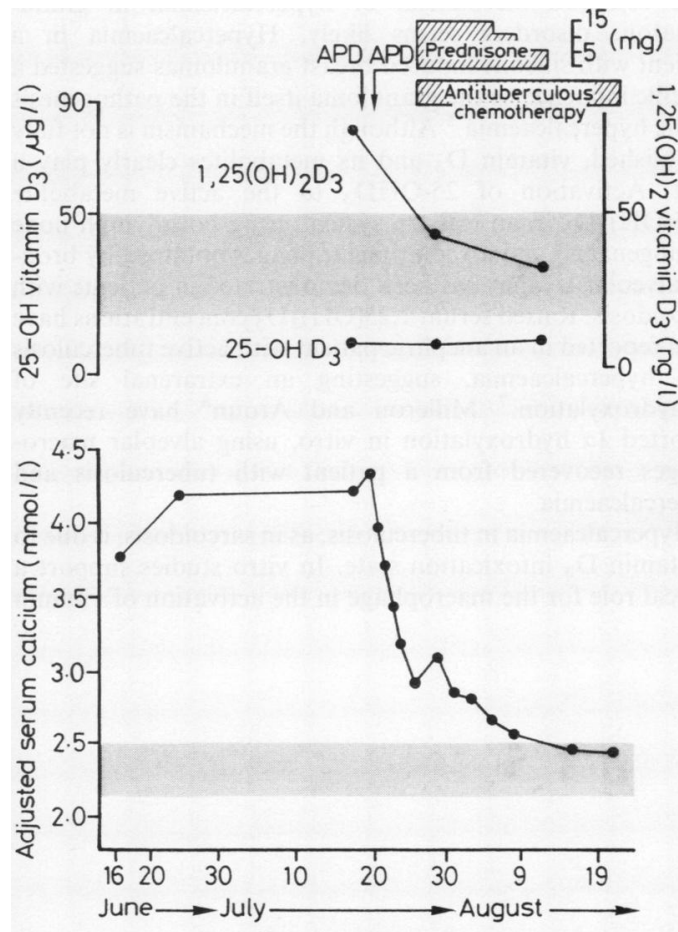

Day of month

Adjusted serum calcium and vitamin $D$ concentrations and response to treatment. Calcium concentrations are adjusted to a mean albumin concentration of $40 \mathrm{~g} / \mathrm{l}$ (normal ranges indicated by shaded areas).

miliary tuberculosis antituberculous treatment with isoniazid, rifampicin, and pyrazinamide was started. Prednisone was given in decreasing dosage (figure). The serum calcium concentration fell to normal and the improvement was maintained after withdrawal of the steroids. The fall in serum calcium with diphosphonate and steroids was accompanied by a fall in $1,25(\mathrm{OH})_{2} \mathrm{D}_{3}$ levels. One month later he was normocalcaemic and clinically well.

\section{Discussion}

This report describes a patient with culture proved miliary tuberculosis, who at the time of diagnosis was hypercalaemic, and in whom investigations failed to detect any 
cause for the hypercalcaemia other than tuberculosis. The abnormalities in vitamin $D_{3}$ concentration are consistent with activation of the $1 \alpha$-hydroxylation pathway. Prompt falls in serum calcium concentration after therapeutic intervention, initially with diphosphonate and later with prednisone, were associated with falls in $1,25(\mathrm{OH})_{2} \mathrm{D}_{3}$ concentrations, and suggest a dominant role of vitamin $D_{3}$ in the pathogenesis of the hypercalcaemia. Failure to suppress parathyroid hormone in the face of hypercalcaemia, however, suggests that partial autonomy of parathyroid hormone production may have been a contributing factor in this patient.

A common mechanism of hypercalcaemia in granulomatous disorders seems likely. Hypercalcaemia in a patient with silicone induced breast granulomas suggested a specific influence of the granuloma itself in the pathogenesis of the hypercalcaemia. ${ }^{5}$ Although the mechanism is not fully established, vitamin $D_{3}$ and its metabolites clearly play a part. Activation of $25-\mathrm{OHD}_{3}$ to the active metabolite $1,25(\mathrm{OH})_{2} \mathrm{D}_{3}$ in an in vitro system using both lymph node homogenates ${ }^{6}$ and alveolar macrophages obtained by bronchoalveolar lavage ${ }^{1}$ has been demonstrated in patients with sarcoidosis. Raised serum $1,25(\mathrm{OH})_{2} \mathrm{D}_{3}$ concentrations have been reported in an anephric patient with active tuberculosis and hypercalcaemia, suggesting an extrarenal site of $1 \alpha$-hydroxylation. ${ }^{7}$ Milleron and Aroun $^{8}$ have recently reported $1 \alpha$ hydroxylation in vitro, using alveolar macrophages recovered from a patient with tuberculosis and hypercalcaemia.

Hypercalcaemia in tuberculosis, as in sarcoidosis, is due to a vitamin $D_{3}$ intoxication state. In vitro studies support a critical role for the macrophage in the activation of vitamin
D by $1 \alpha$-hydroxylation. Corticosteroids reduce the concen $\times$ tration of $1,25(\mathrm{OH})_{2} \mathrm{D}_{3}$, presumably by inhibiting the hydroxylation step. The changes observed in this patient are consistent with this mechanism, although an additiona? influence from the diphosphonate APD is also possible.

We are grateful to Dr HH Rea for permission to report thi patient.

\section{References}

1 Adams JS, Sharma OP, Mercedes AG, Singer FR. Metabolism oफ 25-hydroxyvitamin $D_{3}$ by cultured pulmonary alveolar macro phages in sarcoidosis. J Clin Invest 1983;72:1856-60.

2 Abbasi AA, Chemplavil JK, Farah S, Muller BF, Arnstein AR Hypercalcemia in active pulmonary tuberculosis. Ann Intern Med 1979;90:324-8.

3 Shai F, Baker RK, Addrizzo JR, Wallach S. Hypercalcemia if mycobacterial infection. J Clin Endocrinol Metab 1972 34:251-6.

4 Sharma OP, Lamon J, Winsor D. Hypercalcemia and tuber-culosis. JAMA 1972;222:582.

5 Kozeny GA, Barbato AL, Bansal VK, Vertuno LL, Hano J卧 Hypercalcemia associated with silicone-induced granulomas. N Engl J Med 1984;311:1103-5.

6 Mason RS, Frankel T, Chan Y-L, Lissner D, Posen S. Vitamin 1 conversion by sarcoid lymph node homogenate. Ann Intern Med 1984;100:59-61.

7 Gkonos PJ, London R, Henler ED. Hypercalcemia and elevated 1,25-dihydroxyvitamin $D$ levels in a patient with end-stag? renal disease and active tuberculosis. $N$ Engl $J$ Meg 1984;311:1683-5.

8 Milleron JCB, Aroun MGG. Serum concentrations of vitamin metabolites in untreated tuberculosis. Thorax 1985;40:639-40 